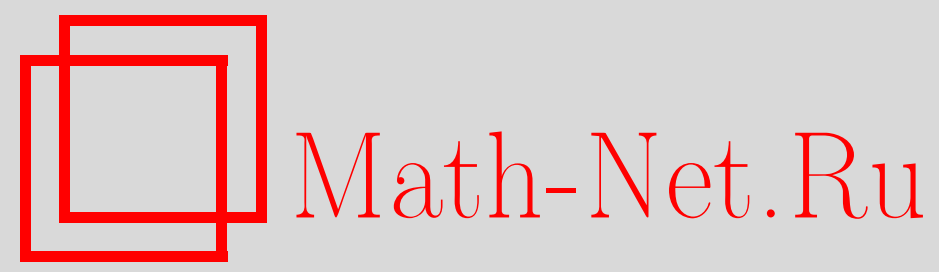

B. Roos, Metric multivariate Poisson approximation of the generalized multinomial distribution, Теория вероятн. и ее примен., 1998, том 43, выпуск 2, 404-413

DOI: https://doi.org/10.4213/tvp1480

Использование Общероссийского математического портала Math-Net.Ru подразумевает, что вы прочитали и согласны с пользовательским соглашением http://www . mathnet.ru/rus/agreement

Параметры загрузки:

IP : 3.89 .185 .249

26 апреля 2023 г., 11:28:07

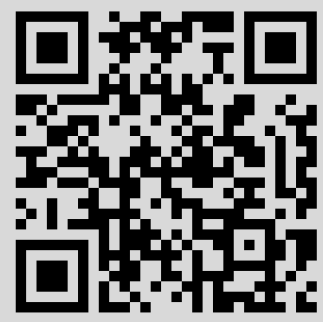


$1998 \mathrm{r}$

ROOS B.*

\section{METRIC MULTIVARIATE POISSON APPROXIMATION OF THE GENERALIZED MULTINOMIAL DISTRIBUTION}

Цель данной статьи - использовать многомерное В-разложение Шарлье для многомерной метрической пуассоновской аппроксимации обобшенного полиномиального распределенкя (см. [3] и [12]). Найдены границы для полной вариация и точечной метрики.

Клюиевые слова и Фразы: пуассоновская аппроксимация, обобшенное полиномиальное распределекие, многомерное В-разложение Шарлье, полная вариация, точечная метрика.

1. Introduction. Let $X_{1}, \ldots, X_{n}(n \in \mathbf{N}=\{1,2, \ldots\})$ be independent random vectors of $\mathbf{R}^{k}, k \in \mathbf{N}$, where $X_{j}=\left(X_{j}(1), \ldots, X_{j}(k)\right), \mathbf{P}\left\{X_{j}=e_{r}\right\}=p_{j, r} \in[0,1]$, and $\mathbf{P}\left\{X_{j}=0\right\}=1-\sum_{r=1}^{k} p_{j, r} \in[0,1]$, for $j \in\{1, \ldots, n\}$ and $r \in\{1, \ldots, k\}$. Here, $e_{r}$ is the vector in $\mathbf{R}^{k}$ with 1 at position $r \in\{1, \ldots, k\}$ and 0 otherwise. For $l \in \mathbf{N}$ and $r \in\{1, \ldots, k\}$, let $\lambda_{l}=\left(\lambda_{l}(1), \ldots, \lambda_{l}(k)\right), \lambda_{l}(r)=\sum_{j=1}^{n} p_{j, r}^{l}>0, \lambda=\lambda_{1}, \theta=$ $(\theta(1), \ldots, \theta(k)), \theta(r)=\lambda_{2}(r) / \lambda(r)$. Set $S_{n}=\sum_{j=1}^{n} X_{j}$. Always, let $0^{0}=1$.

In this paper, the distribution $P^{S_{n}}$ of $S_{n}$ is approximated by the multivariate Poisson distribution $\mathscr{P}(t)$, for $t=\left(t_{1}, \ldots, t_{k}\right) \in(0, \infty)^{k}$, and related finite signed measures of higher order. Here

$$
\mathscr{P}(t)(\{m\})=\exp \left(-\sum_{r=1}^{k} t_{r}\right) \prod_{r=1}^{k} \frac{t_{r}^{m_{r}}}{m_{r} !} \text { for } m=\left(m_{1}, \ldots, m_{k}\right) \in \mathbf{Z}_{+}^{k},
$$

and $\mathbf{Z}_{+}=\{0,1,2, \ldots\}$. As measures of accuracy, the following metrics are considered:

$$
\begin{aligned}
& d_{r}(P, Q)=\sup _{A \subseteq \mathbf{Z}_{+}^{k}}|P(A)-Q(A)|=\frac{1}{2} \sum_{m \in \mathbf{Z}_{+}^{k}}|P(\{m\})-Q(\{m\})| \quad \text { (total variation), } \\
& d_{\pi}(P, Q)=\sup _{m \in \mathbf{Z}_{+}^{k}}|P(\{m\})-Q(\{m\})| \quad \text { (point metric), }
\end{aligned}
$$

where $P$ and $Q$ are finite signed measures concentrated on $\mathbf{Z}_{+}^{k}$ satisfying $P\left(\mathbf{Z}_{+}^{k}\right)=Q\left(\mathbf{Z}_{+}^{k}\right)$.

Various authors treated this approximation problem. The most important papers, concerning the total variation, came from Barbour [3] and Deheuvels and Pfeifer [12], using the Stein-Chen method and the semigroup method originally developed by Le Cam [16], respectively.

Barbour [3] showed that

$$
d_{\tau}\left(P^{S_{n}}, \mathscr{P}(\lambda)\right) \leqslant \sum_{j=1}^{n} \min \left\{\left[\frac{1}{2}+\log ^{+}\left(2 \sum_{r=1}^{k} \lambda(r)\right)\right] \sum_{r=1}^{k} \frac{p_{j, r}^{2}}{\lambda(r)},\left(\sum_{r=1}^{k} p_{j, r}\right)^{2}\right\},
$$

where $\log ^{+}(x)=\max \{0, \log (x)\}$ for $x \in(0, \infty)$. Note that in the case $k=1$, Barbour and Hall [4] proved that

$$
\frac{1}{32} \min \left\{\lambda_{2}(1), \theta(1)\right\} \leqslant d_{\tau}\left(P^{S_{n}}, \mathscr{P}(\lambda)\right) \leqslant\left(1-e^{-\lambda(1)}\right) \theta(1) .
$$

*Institut für Mathematische Stochastik, Universität Hamburg, Bundesstrasse 55, D-20146, Hamburg, Germany. 
Deheuvels and Pfeifer [12] developed some asymptotic formulae, which are too involved to state them here. It should be mentioned that their upper bounds for total variation [see their Theorem 2.2] are only useful for bounded $\sum_{j=1}^{n}\left(\sum_{r=1}^{k} p_{j, r}\right)^{2}$. In the case $k=1$, they used the univariate Charlier B expansion due to Charlier [7] to prove (see [13]):

$$
\begin{aligned}
d_{\tau}\left(P^{S_{n}}, \mathscr{P}(\lambda)\right)= & \frac{1}{2} \lambda_{2}(1) e^{-\lambda(1)} \\
& \times\left(\frac{\lambda(1)^{a-1}}{a !}(a-\lambda(1))+\frac{\lambda(1)^{b-1}}{b !}(\lambda(1)-b)\right)+R
\end{aligned}
$$

where $a=\left\lfloor\lambda(1)+\frac{1}{2}+\sqrt{\lambda(1)+\frac{1}{4}}\right\rfloor, b=\left\lfloor\lambda(1)+\frac{1}{2}-\sqrt{\lambda(1)+\frac{1}{4}}\right\rfloor$ and $|R| \leqslant \sqrt{2} \theta(1)^{3 / 2} /(1-$ $\sqrt{2 \theta(1)})$, for $\theta(1)<\frac{1}{2}(\lfloor x\rfloor \in \mathbf{Z}$ being defined by $x-1<\lfloor x\rfloor \leqslant x, x \in \mathbf{R})$.

Other publications, concerning the multivariate problem, are: [1], [2], [5], [9], [17], [23]-[26].

The univariate setting (i.e., the case $k=1$ ) was investigated by many authors (for instance, see [4], [5], [6], [8], [10], [11], [13]-[16], [18]-[22]).

Various metrics were considered in the univariate setting (for instance, the total variation, Kolmogorov metric, Fortet-Mourier metric, point metric, and $l^{p}$ metric between distribution functions), while in the multivariate case, the total variation and the Kolmogorov metric (for this, see [23]) were treated. Here, the point metric has not been considered before.

The aim of this paper is to introduce the multivariate Charlier B expansion to the given problem. The text refers to the works of Shorgin [22], Deheuvels and Pfeifer [13], and Roos [19], [20] concerning the univariate Poisson approximation with the help of the univariate Charlier B expansion. In Section 2, the multivariate Charlier B expansion of $P^{S_{n}}$ is presented. Formulae and an estimate for the corresponding Charlier coefficients are derived. Section 3 is devoted to the main results. Bounds for the distances between $P^{S} S_{n}$ and Poisson related signed measures in the total variation and point metric are

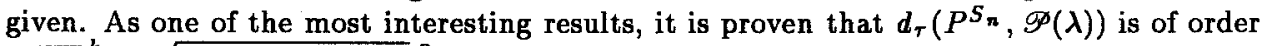
$O\left(\left[\sum_{r=1}^{k} \sqrt{\min \left\{\theta(r), \lambda_{2}(r)\right\}}\right]^{2}\right)$ (see Corollary 1).

Note that the Kolmogorov metric could also have been considered in this paper; but the resulting bounds would have been of the same order as for the total variation and are therefore omitted.

2. The multivariate Charlier $B$ expansion. Let

$$
\pi(m, x)=\frac{e^{-x} x^{m}}{m !} \text { for } m \in \mathbf{Z}_{+}, x \in[0, \infty) .
$$

For $f: \mathbf{Z}_{+} \longrightarrow \mathbf{R}$, let $\Delta f: \mathbf{Z}_{+} \longrightarrow \mathbf{R}$ be defined by $(\Delta f)(m)=f(m-1)-f(m), m \in \mathbf{N}$, and $(\Delta f)(0)=-f(0)$. Further, let $\Delta^{0} f=f$ and $\Delta^{l} f=\Delta\left(\Delta^{l-1} f\right)$ for $l \in \mathbf{N}$. Finally, let $\Delta^{l} \pi(m, x):=\Delta^{l}(\pi(\cdot, x))(m)$ for $m, l \in \mathbf{Z}_{+}, x \in[0, \infty)$. It is easy to show that

$$
\sum_{m=0}^{\infty} \Delta^{l} \pi(m, x) z^{m}=(z-1)^{l} \exp (x(z-1)),
$$

for $l \in \mathbf{Z}_{+}, x \in[0, \infty), z \in \mathbf{C}$, where $\mathbf{C}$ denotes the set of complex numbers. The following lemma gives the main argument of this paper.

Lemma 1. For $m=\left(m_{1}, \ldots, m_{k}\right) \in \mathbf{Z}_{+}^{k}, t=\left(t_{1}, \ldots, t_{k}\right) \in(0, \infty)^{k}$,

$$
\mathbf{P}\left\{S_{n}=m\right\}=\sum_{l_{1}=0}^{\infty} \cdots \sum_{l_{k}=0}^{\infty} a_{l}(t) \prod_{r=1}^{k} \Delta^{l_{r}} \pi\left(m_{r}, t_{r}\right),
$$


where $l$ stands for $\left(l_{1}, \ldots, l_{k}\right)$ and the coefficients $a_{l}(t)$ are defined by

$$
\sum_{l_{1}=0}^{\infty} \cdots \sum_{l_{k}=0}^{\infty} a_{l}(t) z_{1}^{l_{1}} \cdots z_{k}^{l_{k}}=\exp \left(-\sum_{r=1}^{k} t_{r} z_{r}\right) \prod_{j=1}^{n}\left(1+\sum_{r=1}^{k} p_{j, r} z_{r}\right) .
$$

P r o of. Let $\varphi_{S_{n}}: \mathbf{C}^{k} \longrightarrow \mathbf{C}$ denote the probability generating function of $S_{n}$, defined by

$$
\begin{aligned}
\varphi_{S_{n}}(z) & =\sum_{m_{1}=0}^{\infty} \cdots \sum_{m_{k}=0}^{\infty} \mathbf{P}\left\{S_{n}=\left(m_{1}, \ldots, m_{k}\right)\right\} z_{1}^{m_{1}} \cdots z_{k}^{m_{k}} \\
& =\prod_{j=1}^{n}\left(1+\sum_{r=1}^{k} p_{j, r}\left(z_{r}-1\right)\right)
\end{aligned}
$$

for $z=\left(z_{1}, \ldots, z_{k}\right) \in \mathbf{C}^{k}$. By the help of (7), this yields, in case of $\left|z_{r}\right|<1$ for $r \in$ $\{1, \ldots, k\}$,

$$
\begin{aligned}
\varphi_{S_{n}}(z) & =\sum_{l_{1}=0}^{\infty} \cdots \sum_{l_{k}=0}^{\infty} a_{l}(t)\left[\prod_{r=1}^{k}\left(z_{r}-1\right)^{l_{r}}\right] \exp \left(\sum_{r=1}^{k} t_{r}\left(z_{r}-1\right)\right) \\
& =\sum_{l_{1}=0}^{\infty} \cdots \sum_{l_{k}=0}^{\infty} a_{l}(t) \prod_{r=1}^{k}\left[\sum_{m_{r}=0}^{\infty} \Delta^{l_{r}} \pi\left(m_{r}, t_{r}\right) z_{r}^{m_{r}}\right] \\
& =\sum_{m_{1}=0}^{\infty} \cdots \sum_{m_{k}=0}^{\infty}\left[\sum_{l_{1}=0}^{\infty} \cdots \sum_{l_{k}=0}^{\infty} a_{l}(t) \prod_{r=1}^{k} \Delta^{l_{r}} \pi\left(m_{r}, t_{r}\right)\right] z_{1}^{m_{1}} \cdots z_{k}^{m_{k}} .
\end{aligned}
$$

Here, summations may be interchanged, because $\left|\Delta^{l} \pi(m, x)\right| \leqslant 2^{l}$ holds for all $l, m \in \mathbf{Z}_{+}$, $x \in[0, \infty)$, and therefore the iterated series converge absolutely. By comparing the power series, the assertion follows.

By similar considerations as above, one shows that the iterated series (6) converge absolutely, so that, here, the order of summation is not relevant. The series (6) is called Charlier B expansion of $P^{S_{n}}$. The coefficients $a_{l}(t)$ are called Charlier coefficients of $P^{S_{n}}$. In order to derive upper bounds for the total variation and point metric, an inequality for the Charlier coefficients of $P^{S_{n}}$ is needed.

In what follows, we use the notation $s=\sum_{r=1}^{k} l_{r}$ for $\left(l_{1}, \ldots, l_{k}\right) \in \mathbf{Z}_{+}^{k}$, and $\eta\left(r, t_{r}\right)=$ $2 \lambda_{2}(r)+\left(\lambda(r)-t_{r}\right)^{2}$ for $r \in\{1, \ldots, k\}$ and $\left(t_{1}, \ldots, t_{k}\right) \in(0, \infty)^{k}$.

Lemma 2. Let $l=\left(l_{1}, \ldots, l_{k}\right) \in \mathbf{Z}_{+}^{k}, s \geqslant 1, t=\left(t_{1}, \ldots, t_{k}\right) \in(0, \infty)^{k}$. Further, let $I_{0}(x)=\sum_{j=0}^{\infty}(x / 2)^{2 j} /(j !)^{2}$ be the modified Bessel function of the first kind and order 0 and $\beta(x)=I_{0}(x) e^{-x^{2} / 4}, x \in \mathbf{R}$. Then

$$
\left|a_{i}(t)\right| \leqslant \prod_{r=1}^{k}\left[\frac{\left(\eta\left(r, t_{r}\right) s e\right)^{l_{r} / 2}}{2^{l_{r} / 2} l_{r}^{l_{r}}} \beta\left(\frac{\sqrt{2}\left|\lambda(r)-t_{r}\right| l_{r}}{\sqrt{s \eta\left(r, t_{r}\right)}}\right)\right] .
$$

P r o of. Let $R_{1}, \ldots, R_{k} \in(0, \infty)$. By Cauchy's theorem,

$$
\begin{aligned}
a_{l}(t)=\frac{1}{(2 \pi)^{k} R_{1}^{l_{1}} \cdots R_{k}^{l_{k}}} \int_{-\pi}^{\pi} \cdots \int_{-\pi}^{\pi} h\left(R_{1} e^{i x_{1}}, \ldots, R_{k} e^{i x_{k}}\right) \\
\quad \times \exp \left(-i \sum_{r=1}^{k} l_{r} x_{r}\right) d x_{1} \cdots d x_{k}
\end{aligned}
$$


where

$$
h(z)=\varphi_{S_{n}}\left(z_{1}+1, \ldots, z_{k}+1\right) \exp \left(-\sum_{r=1}^{k} t_{r} z_{r}\right), \quad z=\left(z_{1}, \ldots, z_{k}\right) \in \mathbf{C}^{k}
$$

Because $\cos x_{1} \cos x_{2}+\sin x_{1} \sin x_{2}=\cos \left(x_{1}-x_{2}\right), x_{1}, x_{2} \in \mathbf{R}$, and $1+x \leqslant e^{x}, x \in \mathbf{R}$,

$$
\begin{aligned}
& \left|h\left(R_{1} e^{i x_{1}}, \ldots, R_{k} e^{i x_{k}}\right)\right| \leqslant \prod_{j=1}^{n_{k}}\left|1+\sum_{r=1}^{k} p_{j, r} R_{r} e^{i x_{r}}\right|\left|\exp \left(-\sum_{r=1}^{k} t_{r} R_{r} e^{i x_{r}}\right)\right| \\
& =\prod_{j=1}^{n}\left[1+2 \sum_{r=1}^{k} p_{j, r} R_{r} \cos \left(x_{r}\right)+\sum_{r_{1}=1}^{k} \sum_{r_{2}=1}^{k} p_{j, r_{1}} p_{j, r_{2}} R_{r_{1}} R_{r_{2}} \cos \left(x_{r_{1}}-x_{r_{2}}\right)\right]^{1 / 2} \\
& \quad \times \exp \left(-\sum_{r=1}^{k} t_{r} R_{r} \cos \left(x_{r}\right)\right) \\
& \leqslant \exp \left(\sum_{r=1}^{k}\left(\lambda(r)-t_{r}\right) R_{r} \cos \left(x_{r}\right)+\frac{1}{2} \sum_{j=1}^{n}\left[\sum_{r=1}^{k} p_{j, r} R_{r}\right]^{2}\right)
\end{aligned}
$$

Since $I_{0}(x)=(1 / \pi) \int_{0}^{\pi} \exp (x \cos (y)) d y, x \in \mathbf{R}$, this leads to

$$
\begin{aligned}
\left|a_{l}(t)\right| \leqslant & \frac{1}{R_{1}^{l_{1}} \cdots R_{k}^{l_{k}}} \exp \left(\frac{1}{2} \sum_{j=1}^{n}\left[\sum_{r=1}^{k} p_{j, r} R_{r}\right]^{2}+\frac{1}{4} \sum_{r=1}^{k}\left(\lambda(r)-t_{r}\right)^{2} R_{r}^{2}\right) \\
& \times \prod_{r=1}^{k} \beta\left(\left(\lambda(r)-t_{r}\right) R_{r}\right) .
\end{aligned}
$$

Using Cauchy's inequality, the following estimate is valid:

$$
\sum_{j=1}^{n}\left[\sum_{r=1}^{k} p_{j, r} R_{T}\right]^{2}=\sum_{r_{1}=1}^{k} \sum_{r_{2}=1}^{k}\left(\sum_{j=1}^{n} p_{j, r_{1}} p_{j, r_{2}}\right) R_{r_{1}} R_{r_{2}} \leqslant\left(\sum_{r=1}^{k} \sqrt{\lambda_{2}(r)} R_{r}\right)^{2} .
$$

Hence, $\left|a_{l}(t)\right| \leqslant g\left(R_{1}, \ldots, R_{k}\right) \prod_{r=1}^{k} \beta\left(\left(\lambda(r)-t_{r}\right) R_{r}\right)$, where $g:(0, \infty)^{k} \longrightarrow \mathbf{R}$, defined by

$$
g\left(R_{1}, \ldots, R_{k}\right)=\frac{1}{R_{1}^{l_{1}} \cdots R_{k}^{l_{k}}} \exp \left(\frac{1}{2}\left[\sum_{r=1}^{k} \sqrt{\frac{\eta\left(r, t_{r}\right)}{2}} R_{r}\right]^{2}\right)
$$

attains its minimum for $\widetilde{R}=\left(\widetilde{R}_{1}, \ldots, \widetilde{R}_{k}\right), \widetilde{R}_{r}=\sqrt{2} l_{r} / \sqrt{s \eta\left(r, t_{r}\right)}, r \in\{1, \ldots, k\}$. Substituting $\widetilde{R}$ for $\left(R_{1}, \ldots, R_{k}\right)$, the desired result is shown.

Note that $0<\beta(x)=\beta(|x|) \leqslant 1, x \in \mathbf{R}$. The next lemma gives a recursive formula for the Charlier coefficients of $P^{S_{n}}$. Lemmata 2 and 3 are multivariate generalizations of results of [19], [20] (for $k=1$ and arbitrary $t$ ) and [22] (for $k=1$ and $t=\lambda$ ).

Lemma 3. Let $b \in\{1, \ldots, k\}, l=\left(l_{1}, \ldots, l_{k}\right) \in \mathbf{Z}_{+}^{k}, l_{b} \geqslant 1, t=\left(t_{1}, \ldots, t_{k}\right) \in$ $(0, \infty)^{k}$. Then

$$
\begin{gathered}
a_{l}(t)=-\frac{t_{b}}{l_{b}} a_{l-e_{b}}(t)-\frac{1}{l_{b}} \sum_{j \in A} \frac{l_{b}-j_{b}}{s-J}\left(\begin{array}{c}
s-J \\
l_{1}-j_{1}, \ldots, l_{k}-j_{k}
\end{array}\right)(-1)^{s+J} \\
\times a_{j}(t)\left[\sum_{i=1}^{n} \prod_{r=1}^{k} p_{i, r}^{l_{r}-j_{r}}\right]
\end{gathered}
$$


where $A$ denotes the set of all $j=\left(j_{1}, \ldots, j_{k}\right) \in \mathbf{Z}_{+}^{k}$ such that $0 \leqslant j_{r} \leqslant l_{r}$ for $r \in$ $\{1, \ldots, k\} \backslash\{b\}$ and $0 \leqslant j_{b} \leqslant l_{b}-1$, and further $J$ is the sum $\sum_{r=1}^{k} j_{r}$.

$\mathrm{P} \mathrm{r} \circ$ o $\mathrm{f}$. It suffices to prove the assertion for $b=1$. Let

$$
\begin{aligned}
z & =\left(z_{1}, \ldots, z_{k}\right) \in(-1,1)^{k}, \quad g(z)=\exp (f(z)), \\
f(z) & =-\sum_{r=1}^{k} t_{r} z_{r}+\sum_{j=1}^{n} \ln \left(1+\sum_{r=1}^{k} p_{j, r} z_{r}\right)
\end{aligned}
$$

Then

$$
\begin{aligned}
\frac{\partial^{l_{1}+\cdots+l_{k}}}{\partial z_{1}^{l_{1}} \cdots \partial z_{k}^{l_{k}}} g(z)= & \sum_{j_{1}=0}^{l_{1}-1}\left(\begin{array}{c}
l_{1}-1 \\
j_{1}
\end{array}\right) \frac{\partial^{l_{2}+\cdots+l_{k}}}{\partial z_{2}^{l_{2}} \cdots \partial z_{k}^{l_{k}}}\left[\frac{\partial^{j_{1}}}{\partial z_{1}^{j_{1}}} g(z) \frac{\partial^{l_{1}-j_{1}}}{\partial z_{1}^{l_{1}-j_{1}}} f(z)\right] \\
= & \sum_{j_{1}=0}^{l_{1}-1} \sum_{j_{2}=0}^{l_{2}} \cdots \sum_{j_{k}=0}^{l_{k}}\left(\begin{array}{c}
l_{1}-1 \\
j_{1}
\end{array}\right)\left(\begin{array}{c}
l_{2} \\
j_{2}
\end{array}\right) \cdots\left(\begin{array}{c}
l_{k} \\
j_{k}
\end{array}\right) \\
& \times \frac{\partial^{j_{1}+\cdots+j_{k}}}{\partial z_{1}^{j_{1}} \cdots \partial z_{k}^{j_{k}}} g(z) \frac{\partial^{\left(l_{1}-j_{1}\right)+\cdots+\left(l_{k}-j_{k}\right)}}{\partial z_{1}^{l_{1}-j_{1}} \cdots \partial z_{k}^{l_{k}-j_{k}}} f(z) .
\end{aligned}
$$

Hence,

$$
\begin{aligned}
& a_{l}(t)=\left.\frac{1}{\prod_{r=1}^{k}\left(l_{r} !\right)} \frac{\partial^{l_{1}+\cdots+l_{k}}}{\partial z_{1}^{l_{1}} \cdots \partial z_{k}^{l_{k}}} g(z)\right|_{z=0} \\
&=\frac{1}{l_{1}} \sum_{j_{1}=0}^{l_{1}-1} \sum_{j_{2}=0}^{l_{2}} \cdots \sum_{j_{k}=0}^{l_{k}} \frac{a_{j}(t)}{\left(l_{1}-1-j_{1}\right) !\left(l_{2}-j_{2}\right) ! \cdots\left(l_{k}-j_{k}\right) !} \\
& \quad \times\left.\frac{\partial^{\left(l_{1}-j_{1}\right)+\cdots+\left(l_{k}-j_{k}\right)}}{\partial z_{1}^{l_{1}-j_{1}} \cdots \partial z_{k}^{l_{k}-j_{k}}} f(z)\right|_{z=0}
\end{aligned}
$$

Since

$$
\left.\frac{\partial^{l_{1}+\cdots+l_{k}}}{\partial z_{1}^{l_{1}} \cdots \partial z_{k}^{l_{k}}} f(z)\right|_{z=0}=\left\{\begin{array}{l}
\lambda(c)-t_{c} \\
\text { if }\left(l_{1}, \ldots, l_{k}\right)=e_{c}, \quad c \in\{1, \ldots, k\} \\
\sum_{j=1}^{n}\left(\prod_{r=1}^{k} p_{j, r}^{l_{r}}\right)(s-1) !(-1)^{s-1} \\
\text { otherwise, }
\end{array}\right.
$$

for $\left(l_{1}, \ldots, l_{k}\right) \in \mathbf{Z}_{+}^{k}, s \geqslant 1$, the assertion follows immediately.

It is clear that $a_{0}(t)=1$ and, as the preceeding lemma shows, for $r, v \in\{1, \ldots, k\}$, $r \neq v, t=\left(t_{1}, \ldots, t_{k}\right) \in(0, \infty)^{k}$,

$$
\begin{aligned}
a_{e_{r}}(t) & =\lambda(r)-t_{r} \\
a_{2 e_{r}}(t) & =\frac{1}{2}\left(\left(\lambda(r)-t_{r}\right)^{2}-\lambda_{2}(r)\right) \\
a_{e_{r}+e_{v}}(t) & =\left(\lambda(r)-t_{r}\right)\left(\lambda(v)-t_{v}\right)-\sum_{j=1}^{n} p_{j, r} p_{j, v} .
\end{aligned}
$$

3. Main results. For the first main result of this paper, the next technical lemma is necessary.

Lemma 4. Let $k \in \mathbf{N}, l_{1}, \ldots, l_{k} \in \mathbf{Z}_{+}$. Then

$$
\frac{s^{s}}{\prod_{r=1}^{k} l_{r}^{l_{r}}} \leqslant\left(\frac{s !}{\prod_{r=1}^{k}\left(l_{r} !\right)}\right)^{2}=\left(\begin{array}{c}
s \\
l_{1}, \ldots, l_{k}
\end{array}\right)^{2}
$$


P r $\circ \circ$ f. It suffices to assume that $l_{1}, \ldots, l_{k} \in \mathrm{N}, k \in\{2,3, \ldots\}$. Then

$$
\frac{s^{s}}{\prod_{r=1}^{k} l_{r}^{l_{r}}}=\prod_{r=1}^{k-1} \frac{u_{r+1}^{u_{r+1}}}{u_{r}^{u_{r}} l_{r+1}^{l_{r+1}}}
$$

where $u_{r}=\sum_{m=1}^{r} l_{m}$ for $r \in\{1, \ldots, k\}$. For $a \in \mathbf{N}, b \in\{1, \ldots, a-1\}$,

$$
\frac{a^{a}}{b^{b}(a-b)^{a-b}}=\left(\frac{a}{b}\right)^{b}\left(\frac{a}{a-b}\right)^{a-b} \leqslant\left[\prod_{m=1}^{b} \frac{a-m+1}{b-m+1}\right]\left[\prod_{m=1}^{a-b} \frac{a-m+1}{a-b-m+1}\right]=\left(\begin{array}{l}
a \\
b
\end{array}\right)^{2}
$$

The proof is easily completed.

For $f: \mathbf{Z}_{+} \longrightarrow \mathbf{R}$, let

$$
\|f\|_{\infty}=\sup _{m \in \mathbf{Z}_{+}}|f(m)| \text { and }\|f\|_{1}=\sum_{m=0}^{\infty}|f(m)| .
$$

Theorem 1. Let

$$
t=\left(t_{1}, \ldots, t_{k}\right) \in(0, \infty)^{k} \quad \text { and } \quad \gamma\left(r, t_{r}\right)=\eta\left(r, t_{r}\right) \min \left\{\frac{1}{2 t_{r}}, e\right\}
$$

for $r \in\{1, \ldots, k\}$. If $\sum_{r=1}^{k} \sqrt{2 \gamma\left(r, t_{r}\right)}<1$ then

$$
d_{\tau}\left(P^{S_{n}}, \mathscr{P}(t)\right) \leqslant \sum_{r=1}^{k}\left|\lambda(r)-t_{r}\right| \min \left\{\left(2 t_{r} e\right)^{-1 / 2}, 1\right\}+\frac{\left(\sum_{r=1}^{k} \sqrt{\gamma\left(r, t_{r}\right)}\right)^{2}}{1-\sum_{r=1}^{k} \sqrt{2 \gamma\left(r, t_{r}\right)}} .
$$

If $Q(u, t)$ denotes the finite signed measure concentrated on $\mathbf{Z}_{+}^{k}$ with counting density

$$
Q(u, t)(\{m\})=\sum_{s=0}^{u} \sum_{l \in A_{s}}\left[a_{l}(t) \prod_{r=1}^{k} \Delta^{l_{r}} \pi\left(m_{r}, t_{r}\right)\right]
$$

for $m=\left(m_{1}, \ldots, m_{k}\right) \in \mathbf{Z}_{+}^{k}$, where $u \in \mathbf{N}$ and $A_{s}=\left\{\left(l_{1}, \ldots, l_{k}\right) \in \mathbf{Z}_{+}^{k} \mid \sum_{r=1}^{k} l_{r}=s\right\}$ for $s \in \mathbf{Z}_{+}$, then, in the case $\sum_{r=1}^{k} \sqrt{2 \gamma\left(r, t_{r}\right)}<1$,

$$
d_{\tau}\left(P^{S_{n}}, Q(u, t)\right) \leqslant 2^{(u-1) / 2} \frac{\left(\sum_{r=1}^{k} \sqrt{\gamma\left(r, t_{r}\right)}\right)^{u+1}}{1-\sum_{r=1}^{k} \sqrt{2 \gamma\left(r, t_{r}\right)}}
$$

P r o o f. Let

$$
T=\sum_{r=1}^{k}\left|\lambda(r)-t_{r}\right| \min \left\{\left(2 t_{r} e\right)^{-1 / 2}, 1\right\}
$$

By the use of

$$
\left\|\Delta^{b} \pi(\cdot, x)\right\|_{1} \leqslant \min \left\{\left[\frac{2 b}{x e}\right]^{b / 2}, 2^{b}\right\}, \quad x \in(0, \infty), \quad b \in \mathbf{Z}_{+}
$$

(see [13]) in addition to (6), (8), (11), and (14), the inequality (15) is shown as follows. Assume that

$$
\sum_{r=1}^{k} \sqrt{2 \gamma\left(r, t_{r}\right)}<i
$$


then

$$
\begin{aligned}
d_{\tau}\left(P^{S_{n}}, \not \supset(t)\right) & \leqslant \frac{1}{2} \sum_{m \in \mathbf{Z}_{+}^{k}}\left|\sum_{l \in \mathbf{Z}_{+}^{k} \backslash A_{0}} a_{r}(t) \prod_{r=1}^{k} \Delta^{l_{r}} \pi\left(m_{r}, t_{r}\right)\right| \\
& \leqslant \frac{1}{2} \sum_{i \in \mathbf{Z}_{+}^{k} \backslash A_{0}}\left|a_{l}(t)\right| \prod_{r=1}^{k}\left\|\Delta^{l_{r}} \pi\left(\cdot, t_{r}\right)\right\|_{1} \\
& \leqslant T+\frac{1}{2} \sum_{s=2}^{\infty} \sum_{l \in A_{s}} \prod_{r=1}^{k}\left[\frac{\left(\eta\left(r, t_{r}\right) s e\right)^{l_{r} / 2}}{2^{l_{r} / 2} l_{r}^{l_{r}}} \min \left\{\left(\frac{2 l_{r}}{t_{r} e}\right)^{l_{r} / 2}, 2^{l_{r}}\right\}\right] \\
& \leqslant T+\frac{1}{2} \sum_{s=2}^{\infty} \sum_{l \in A_{s}}\left(t_{1}, \ldots, l_{k}\right) \prod_{r=1}^{k}\left(2 \gamma\left(r, t_{r}\right)\right)^{l_{r} / 2} \\
& =T+\frac{\left(\sum_{r=1}^{k} \sqrt{\left.\gamma\left(r, t_{r}\right)\right)^{2}}\right.}{1-\sum_{r=1}^{k} \sqrt{2 \gamma\left(r, t_{r}\right)}}
\end{aligned}
$$

The rest of the assertion is proven analogously.

It is easy to verify that $Q(1, \lambda)=\mathscr{P}(\lambda)$ and, for $m=\left(m_{1}, \ldots, m_{k}\right) \in \mathbf{Z}_{+}^{k}, t=$ $\left(t_{1}, \ldots, t_{k}\right) \in(0, \infty)^{k}$,

$$
\begin{aligned}
Q(1, t)(\{m\})= & {\left[\prod_{r=1}^{k} \pi\left(m_{r}, t_{r}\right)\right]\left[1+\sum_{r=1}^{k} \frac{1}{t_{r}}\left(\lambda(r)-t_{r}\right)\left(m_{r}-t_{r}\right)\right] } \\
Q(2, t)(\{m\})= & {\left[\prod_{r=1}^{k} \pi\left(m_{r}, t_{r}\right)\right]\left[1+\sum_{r=1}^{k} \frac{1}{t_{r}}\left(\lambda(r)-t_{r}\right)\left(m_{r}-t_{r}\right)\right.} \\
& +\frac{1}{2}\left(\sum_{r=1}^{k} \frac{1}{t_{r}}\left(\lambda(r)-t_{r}\right)\left(m_{r}-t_{r}\right)\right)^{2}-\frac{1}{2} \sum_{j=1}^{n}\left(\sum_{r=1}^{k} \frac{p_{j, r}\left(m_{r}-t_{r}\right)}{t_{r}}\right)^{2} \\
& \left.-\frac{1}{2} \sum_{r=1}^{k} \frac{m_{r}}{t_{r}^{2}}\left[\left(\lambda(r)-t_{r}\right)^{2}-\lambda_{2}(r)\right]\right]
\end{aligned}
$$

As a consequence of Theorem 1,

$$
d_{r}\left(P^{S_{n}}, \not \supset(\lambda)\right) \leqslant \frac{\left(\sum_{r=1}^{k} \sqrt{\gamma(r)}\right)^{2}}{1-\sum_{r=1}^{k} \sqrt{2 \gamma(r)}} \text { if } \sum_{r=1}^{k} \sqrt{2 \gamma(r)}<1,
$$

where $\gamma(r)=\gamma(r, \lambda(r)), r \in\{1, \ldots, k\}$. The following corollary shows that the singularity in (20) can be removed.

Corollary 1. Let

$$
\delta(r)=\min \left\{\theta(r), \lambda_{2}(r)\right\}
$$

for $r \in\{1, \ldots, k\}$. Then

$$
\frac{1}{32} \max _{1 \leqslant r \leqslant k} \delta(r) \leqslant d_{\tau}\left(P^{S_{n}}, \mathscr{P}(\lambda)\right) \leqslant \frac{1}{2-\sqrt{3}}\left(\sum_{r=1}^{k} \sqrt{\gamma(r)}\right)^{2} \leqslant \frac{2 k e}{2-\sqrt{3}} \sum_{r=1}^{k} \delta(r) .
$$

$\mathrm{P}$ r o o f. The first inequality is shown as follows. For $r \in\{1, \ldots, k\}$,

$$
\begin{aligned}
\boldsymbol{d}_{\tau}\left(P^{S_{n}}, \mathscr{P}(\lambda)\right) & \geqslant \sup _{A \subseteq \mathbf{Z}_{+}}\left|\mathbf{P}\left\{S_{n} \in \mathbf{Z}_{+}^{r-1} \times A \times \mathbf{Z}_{+}^{k-r}\right\}-\mathscr{P}(\lambda)\left(\mathbf{Z}_{+}^{r-1} \times A \times \mathbf{Z}_{+}^{k-r}\right)\right| \\
& =d_{r}\left(\mathscr{P} \mathscr{B}\left(n ; p_{1, r}, \ldots, p_{n, r}\right), \mathscr{P}(\lambda(r))\right)
\end{aligned}
$$


where $\mathscr{P} \mathscr{B}\left(n ; p_{1, r}, \ldots, p_{n, r}\right)$ is the Poisson binomial distribution with parameters $n \in \mathbf{N}$, $p_{1, r}, \ldots, p_{n, r} \in[0,1]$, i.e., the distribution of the sum of $n$ independent random variables $Y_{1}, \ldots, Y_{n}$ with $\mathbf{P}\left\{Y_{j}=1\right\}=1-\mathbf{P}\left\{Y_{j}=0\right\}=p_{j, r}, j \in\{1, \ldots, n\}$. Hence, using a lower bound for the latter term obtained by Barbour and Hall [4],

$$
d_{\tau}\left(p^{S_{n}}, \mathscr{P}(\lambda)\right) \geqslant \frac{1}{32} \max _{1 \leqslant r \leqslant k} \delta(r) .
$$

For the second inequality, it suffices to assume that $x:=\sum_{r=1}^{k} \sqrt{2 \gamma(r)}<1$. But in

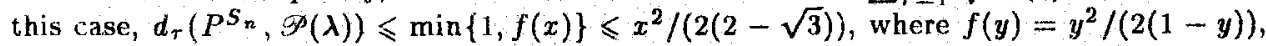
$y \in[0,1)$. By application of Cauchy's inequality, the third inequality is shown.

By Corollary 1 and

$$
\frac{1}{k}\left(\sum_{r=1}^{k} \theta(r)\right)^{2} \leqslant \sum_{r=1}^{k} \theta(r)^{2} \leqslant \sum_{r=1}^{k} \delta(r) \leqslant \sum_{r=1}^{k} \theta(r)
$$

it follows that, for fixed or bounded $k, d_{\tau}\left(P^{S_{n}}, \mathscr{P}(\lambda)\right)$ tends to zero if and only if $\sum_{r=1}^{k} \theta(r)$ tends to zero.

In the general case, one cannot remove the factor $k$ from the right hand side of (21): An inequality of type

$$
d_{r}\left(P^{S_{n}}, \mathscr{g}(\lambda)\right) \leqslant M k^{\alpha} \sum_{r=1}^{k} \delta(r)
$$

with absolute constants $M \in(0, \infty)$ and $\alpha \in[0,1)$ cannot hold. In order to verify this assertion, let, for example, $p_{j, r}=1 /(k n)$ for all $j \in\{1, \ldots, n\}, r \in\{1, \ldots, k\}$. Using an identity by Deheuvels and Pfeifer [12, Lemma 5.1] in addition to an asymptotic result by Deheuvels and Pfeifer [11], $d_{\tau}\left(P^{S}, \mathscr{P}(\lambda)\right)=d_{r}\left(\mathscr{B}(n, 1 / n), \mathscr{\not}^{\varnothing}(1)\right) \sim 3 /(4 e n), n \rightarrow \infty$.

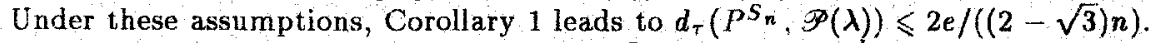

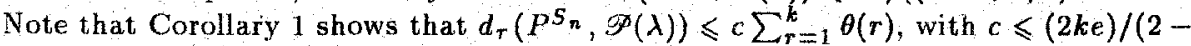
$\sqrt{3})$, whereas Barbour's result (3) implies

$$
c \leqslant \frac{1}{2}+\log +\left(2 \sum_{r=1}^{k} \lambda(r)\right) .
$$

The next result concerns the point metric, for which the following lemma is needed.

Lemma 5. The following inequalities are valid:

$$
\left\|\Delta^{\prime} \pi(\cdot, x)\right\|_{\infty} \leqslant \min \left\{c\left[\frac{l}{x e}\right]^{(l+1) / 2}, 2^{l}\right\}, \quad l \in \mathrm{N}, x \in(0, \infty),
$$

where $c=(\sqrt{e} / 2)(1+\sqrt{\pi / 2})$,

$$
\left\|\Delta^{0} \pi(, x)\right\|_{\infty} \leqslant \min \left\{(2 x e)^{-1 / 2}, 1\right\}, \quad x \in(0, \infty)
$$

P r o f. First, note that

$$
\left\|\Delta^{l} \pi(, x)\right\|_{\infty} \leqslant\left\|\Delta^{l} \pi(, x)\right\|_{1} \leqslant 2^{l}, \quad \text { for } l \in \mathbf{Z}_{+}, x \in[0, \infty)
$$

The rest of (22) and (23) are results of Shorgin [22] and Deheuvels and Pfeifer [13], respectively.

Note that a result by Roos [19, Satz 6.31] (being published in a subsequent paper) asserts that (22) remains valid if $c$ is replaced by $\frac{\sqrt{e}}{2}(1+\sqrt{\pi / 8})$.

Theorem 2. Let $t=\left(t_{1}, \ldots, t_{k}\right) \in(0, \infty)^{k}$. Let $c$ be a constant satisfying inequality (22) and

$$
c_{0}=(2 e)^{-1 / 2} \max \{c, 1\} .
$$


Finally, let

$$
H=\sum_{r=1}^{k}\left|\lambda(r)-t_{r}\right| \min \left\{\frac{c}{t_{r} e}, 2\right\} \prod_{\substack{v=1 \\ v \neq r}}^{k} \min \left\{\left(2 t_{v} e\right)^{-1 / 2}, 1\right\} .
$$

If $\sum_{r=1}^{k} \sqrt{2 \gamma\left(r, t_{r}\right)}<1$ then

$$
d_{\pi}\left(P^{S_{n}}, \mathscr{P}(t)\right) \leqslant H+2 c_{0}^{k}\left[\prod_{r=1}^{k} \sqrt{\frac{2 \gamma\left(r, t_{r}\right)}{\eta\left(r, t_{r}\right)}}\right] \frac{\left(\sum_{r=1}^{k} \sqrt{\gamma\left(r, t_{r}\right)}\right)^{2}}{1-\sum_{r=1}^{k} \sqrt{2 \gamma\left(r, t_{r}\right)}} .
$$

If $Q(u, t)$ denotes the finite signed measure with counting density $(16)$, for $u \in \mathbf{N}$, then, under assumption of $\sum_{r=1}^{k} \sqrt{2 \gamma\left(r, t_{r}\right)}<1$,

$$
d_{\pi}\left(P^{S_{n}}, Q(u, t)\right) \leqslant 2^{(u+1) / 2} c_{0}^{k}\left[\prod_{r=1}^{k} \sqrt{\frac{2 \gamma\left(r, t_{r}\right)}{\eta\left(r, t_{r}\right)}}\right] \frac{\left(\sum_{r=1}^{k} \sqrt{\gamma\left(r, t_{r}\right)}\right)^{u+1}}{1-\sum_{r=1}^{k} \sqrt{2 \gamma\left(r, t_{r}\right)}} .
$$

$\mathrm{P} \mathrm{r}$ o $\circ \mathrm{f}$. Let $A_{s}$ be defined as in Theorem 1 and assume that

$$
\sum_{r=1}^{k} \sqrt{2 \gamma\left(r, t_{r}\right)}<1
$$

Using (6), (11), (22), (23), (8), (14) and $b \leqslant 2^{b-1}, b \in \mathbf{N}$, the assertion follows as in the proof of Theorem 1:

$$
\begin{aligned}
d_{\pi}\left(P^{S_{n}}, \mathscr{P}(t)\right) & \leqslant H+\sum_{s=2}^{\infty} \sum_{l \in A_{s}} \prod_{r=1}^{k}\left[\frac{\left(\eta\left(r, t_{r}\right) s e\right)^{l_{r} / 2}}{2^{l_{r} / 2} l_{r}^{l_{r}}}\left\|\Delta^{l_{r}} \pi\left(\cdot, t_{r}\right)\right\|_{\infty}\right] \\
& \leqslant H+\sum_{s=2}^{\infty} \sum_{l \in A_{s}} \prod_{r=1}^{k}\left[\frac{s^{l_{r} / 2}}{l_{r}^{l_{r} / 2}} c_{0} \sqrt{\frac{2 \gamma\left(r, t_{r}\right)}{\eta\left(r, t_{r}\right)}}\left(2 \gamma\left(r, t_{r}\right)\right)^{l_{r} / 2}\right] \\
& \leqslant H+2 c_{0}^{k}\left[\prod_{r=1}^{k} \sqrt{\frac{2 \gamma\left(r, t_{r}\right)}{\eta\left(r, t_{r}\right)}}\right] \frac{\left(\sum_{r=1}^{k} \sqrt{\gamma\left(r, t_{r}\right)}\right)^{2}}{1-\sum_{r=1}^{k} \sqrt{2 \gamma\left(r, t_{r}\right)}} .
\end{aligned}
$$

The rest of the assertion is proven analogously.

Theorem 2 yields

$$
d_{x}\left(P^{S_{n}}, \mathscr{P}(\lambda)\right) \leqslant 2 c_{0}^{k}\left[\prod_{r=1}^{k} \sqrt{\frac{\gamma(r)}{\lambda_{2}(r)}}\right] \frac{\left(\sum_{r=1}^{k} \sqrt{\gamma(r)}\right)^{2}}{1-\sum_{r=1}^{k} \sqrt{2 \gamma(r)}} \text { if } \sum_{r=1}^{k} \sqrt{2 \gamma(r)}<1,
$$

where $c_{0}$ is defined as in Theorem 2 . One can assume that $c_{0}<1$.

\section{REFERENCES}

1. Ahmad I. A. On the Poisson approximation of multinomial probabilities. - Statist. Probab. Lett., 1985, v. 3, p. 55-56.

2. Аренбаев $Н$. К. Асимптотическое поведение полиномиального распределения. Теория вероятн. и ее примен., 1976, т. XXI, в. 4, с. 826-831.

3. Barbour A. D. Stein's method and Poisson process convergence. - J. Appl. Probab., 1988, v. 25 A, p. 175-184.

4. Barbour A. D., Hall P. On the rate of Poisson convergence. - Math. Proc. Cambridge Philos. Soc., 1984, v. 95, p. 473-480. 
5. Barbour A. D., Holst L., Janson S. Poisson Approximation. - Oxford: Clarendon Press, 1992, $277 \mathrm{p}$.

6. Боровков $K . A$. Уточнение пуассоновской аппроксимации. - Теория вероятн. и ее примен., 1988, т. XXXIII, в. 2, с. 364-368.

7. Charlier C. V. L. Die zweite Form des Fehlergesetzes. - Ark. Mat. Astr. Fys., 1905, v. 2, 15, p. 1-8.

8. Chen L. H. Y. Poisson approximation for dependent trials. - Ann. Probab., 1975, v. 3, p. 534-545.

9. Chen $L$. H. Y., Roos $M$. Compound Poisson approximation for unbounded functions on a group, with application to large deviations. - Probab. Theory Relat. Fields, 1995 , v. 103 , p. 515-528.

10. Deheuvels $P$., Pfeifer D. A semigroup approach to Poisson approximation. - Ann. Probab., 1986, v. 14, p. 663-676.

11. Deheuvels $P$., Pfeifer $D$. Operator semigroups and Poisson convergence in selected metrics. - Semigroup Forum, 1986, v. 34, p. 203-224. Errata. Semigroup Forum, 1987 , v. 35, p. 251.

12. Deheuvels P.; Pfeifer D. Poisson approximations of multinomial distributions and point processes. - J. Multivariate Anal., 1988, v. 25, p. 65-89.

13. Deheuvels $P$., Pfeifer $D$. On a relationship between Uspensky's theorem and Poisson approximations. - Ann. Inst. Statist. Math., 1988, v. 40, p. 671-681.

14. Kerstan J. Verallgemeinerung eines Satzes von Prochorow und Le Cam. - Z. Wahrscheinlichkeitstheor. verw. Geb., 1964, v. 2, p. 173-179.

15. Круопис Й. У точнение аппроксимации обобщенного биномиального распределения свертками пуассоновских мер. - Литов. матем. сб., 1986, т. 26, с. 53-69.

16. Le Cam L. An approximation theorem for the Poisson binomial distribution. Pacific J. Math., 1960, v. 10, p. 1181-1197.

17. McDonald D. R. On the Poisson approximation to the multinomial distribution. Canad. I. Statist., 1980, v. 8, p. 115-118.

18. Пресман Э. Л. Аппроксимация по вариации распределения суммы независимых бернуллиевских величин законом Пуассона. - Теория вероятн. и ее примен., 1985 , т. XXX, в. 2, c. 391-396.

19. Roos B. Metrische Poisson-Approximation. Ph. D. thesis, Fachbereich Mathematik, Universität Oldenburg, 1996.

20. Roos B. Asymptotics and sharp bounds in the Poisson approximation to the Poisson binomial distribution. Preprint № 96-14. Hamburg: Institut für Mathematische Stochastik, Universität Hamburg, 1996.

21. Serfling R. J. A general Poisson approximation theorem. - Ann. Probab., 1975, v. 3, p. 726-731.

22. ІІораия С. Я. Аппроксимация обобщенного биномиального распределения. Теория вероятн. и ее примен., 1977, т. XXII, в. 4, с. 867-871.

23. Sintes Blanc $A$. On the Poisson approximation for some multinomial distributions. Statist. Probab. Lett., 1991, v. 11, p. 1-6.

24. Wang $Y . H$. Coupling methods in approximation. - Canad. J. Statist., 1986, v. 14, p. 69-74.

25. Wang $Y$. H. A multivariate extension of Poisson's theorem. - Canad. J. Statist, 1989 , v. 17 , p. $241-245$.

26. Witte H.-J. On the optimality of multivariate Poisson approximation. - Stochastic Process. Appl., 1993, v. 44, p. 75-88. 